\title{
Performance Evaluation of MC-CDMa SYSTEM OVER RAYLEIGH FADING CHANNEL
}

\author{
A. M. Abdulsattar ${ }^{1}$, A. D. Alwazzan ${ }^{2}$ and K. M.Quboa ${ }^{2}$ \\ ${ }^{1}$ Alhdba University College, Mousel, Iraq \\ ${ }^{2}$ Mousel University, Mousel, Iraq
}

\begin{abstract}
Multi Carrier Code Division Multiple Access (MC-CDMA) is a well known technique for high speed wireless data transmission. Two advanced technology was included in the MC-CDMA structure, such as orthogonal frequency division multiplex (OFDM) and the code division multiple access (CDMA), so that it benefits from the robustness of OFDM against multipath environment and from the capability of multiuser multiplexing services that is achieved via (CDMA) system. MC-CDMA is a multicarrier spread spectrum system which is classified as the candidate scheme for future mobile radio systems. In this paper MCCDMA system, with Rayleigh fading channel and 16QAM array modulation, was simulated to investigate the effects of different parameters on the system performance, such as processing gain; number of paths; number of users; interleaving; and coding ratio.MC-CDMA performances can be considerably improved by proper selection of these parameters. As expected, results show that MC-CDMA has a better performance over CDMA system.
\end{abstract}

\section{KEYWORDS}

CDMA, OFDM, MC-CDMA, Rayleigh fading, Convolutional Encoder.

\section{INTRODUCTION}

People use mobile not only for making their calls but also to transmit and receive different data types like: music, video, games and many other applications. Due to the large number of people request for different communication services, the multiple access technique has been necessary to deal with all requests. The mobile radio channel is considered as one of the difficult channels to deal with. The multipath effect is one of the complicated problems in mobile radio channel and heavily affects the system performance due to the effect of Inter symbol Interference (ISI). Many communication systems used techniques that are known as orthogonal frequency division multiplexing (OFDM) and code division multiple access (CDMA) [1]. OFDM and CDMA techniques are used in high speed wireless communications. One of the advanced technique for broadband wireless communication is Multi-Carrier Code Division Multiple Access (MCCDMA)[2]. MC-CDMA system benefits from the robustness of OFDM against multipath environment and from the capability of multiuser multiplexing services that is achieved via (CDMA)system[2,3].In this paper MC-CDMA performance under Rayleigh fading channelusing16-QAM array modulation, was evaluated for different system parameters such as number of users, number of paths, processing gain, ratio of convolutional encoder, and interleaver.

\section{MC-CDMA SYSTEM}

To support high data rates services, several 4G systems utilizes MC-CDMA to minimize the inter symbol interference (ISI) that occurs when transmission through multipath wireless channels are 
used. The OFDM, as a kind of multicarrier modulation, is an efficient low complex technique modulated multiple subcarriers using digital signal processing (DSP). A multiple parallel low-rate sub-streams was achieved by the multi-carrier system through serial to parallel conversion of the high data rate stream already injected at system input. Each sub-stream is modulated on a different sub-carrier as shown in Figure 1.

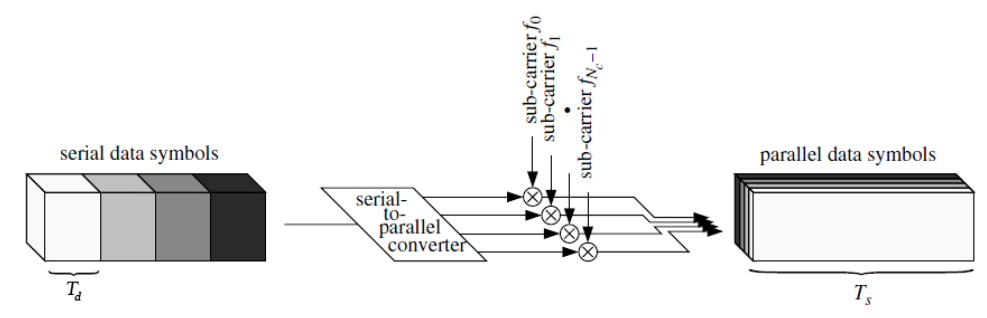

Figure 1. Basic diagram of an Multicarrier System .

One of the important targets in using multicarrier transmission based on OFDM technique is that the mobile radio channel can be considered as time-invariant during one OFDM symbol with flat type fading which is already considered here in this paper by assuming Rayleigh fading channel [4].

\subsection{Reverse Link DS-CDMa System Model}

A mathematical description of a reverse link DS-CDMA system will be discussed here. The main system configuration, including transmitting and receiving side (base station), is shown in Figure 2.

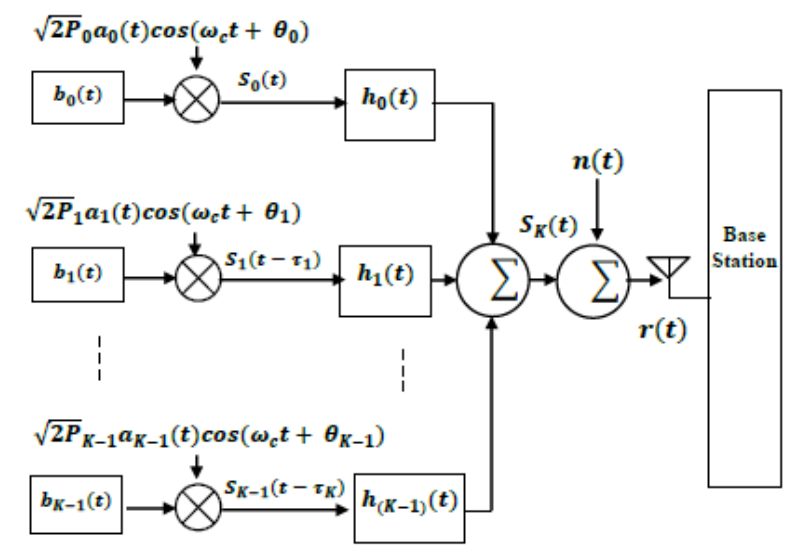

Figure 2. Reverse link DS-CDMA System Model.

Let us considering $\mathrm{K}$ independent users each of them transmits a signal in the form.

$$
S_{k}\left(t-\tau_{k}\right)=\sqrt{2 P_{K}} b_{k}\left(t-\tau_{k}\right) a_{k}\left(t-\tau_{k}\right) \operatorname{Cos}\left(w_{c} t+\theta_{k}\right)
$$

Where $P_{K}$ is the power of the transmitted signal, $b_{k}$ represents thedata bit stream sequence, $a_{k}(t)$ represents the spreading pseudorandom sequence, $w_{c}$ represents the angular frequency of the modulated carrier. Due to asynchronous uplink transmission, the lack of synchronism between different transmitters represented here by the time delay $\tau_{k}, \theta_{k}$ represents the phase angle of the $k^{\text {th }}$ carrier. The $k^{\text {th }}$ user's data signal is an NRZ-L sequence of duration $T_{b}$, taking 
values $\{-1,+1\}$. If $T_{c}$ is the chip period, then $N_{c}=\frac{T_{b}}{T_{c}}$ is the processing gain (PG) or the spreading factor for user $\mathrm{k}$. By considering the desired user as $\mathrm{k}=0$, then the introduced multiple access interference (MAI) comes mainly from the contribution of all other users. Equation (2) gives the signal formula at the input of the receiver.

$$
r_{k}(t)=h_{k}(t) S_{k}(t)+n(t)
$$

Where $h_{k}(t)$ is the complex low pass equivalent impulse response of the the transmitted channel and $n(t)$ is Additive White Gaussian Noise (AWGN). Equation (3) gives the formula of the signal at the input of the receiver after Considering (1) and (2)[5] [6].

$$
\begin{gathered}
r_{k}(t)=\sum_{k=0}^{K-1} \sum_{l_{k}=1}^{L_{k}} \sqrt{2 P_{k}} \alpha_{k, l_{k}} b_{k}\left(t-\tau_{k, l_{k}}\right) \times a_{k}(t) \cos \left(t-\tau_{k, l_{k}}\right) \cos \left(\omega_{c} t+\Phi_{k, l_{k}}\right) \\
+n(t)
\end{gathered}
$$

Where $\emptyset_{k, l_{k}}$ is the phase of the multipath component, $\tau_{k, l_{k}}$ is the path delay, and $L_{k}$ is the number of multipath components. $\alpha_{\mathrm{k}, l_{k}}$ is a random process with Rayleigh distribution which represents the magnitude of the $l^{\text {th }}$ multipath .

\subsection{OFDM BASIC SYSTEM}

The OFDM system block diagram is shown in Figure 3.

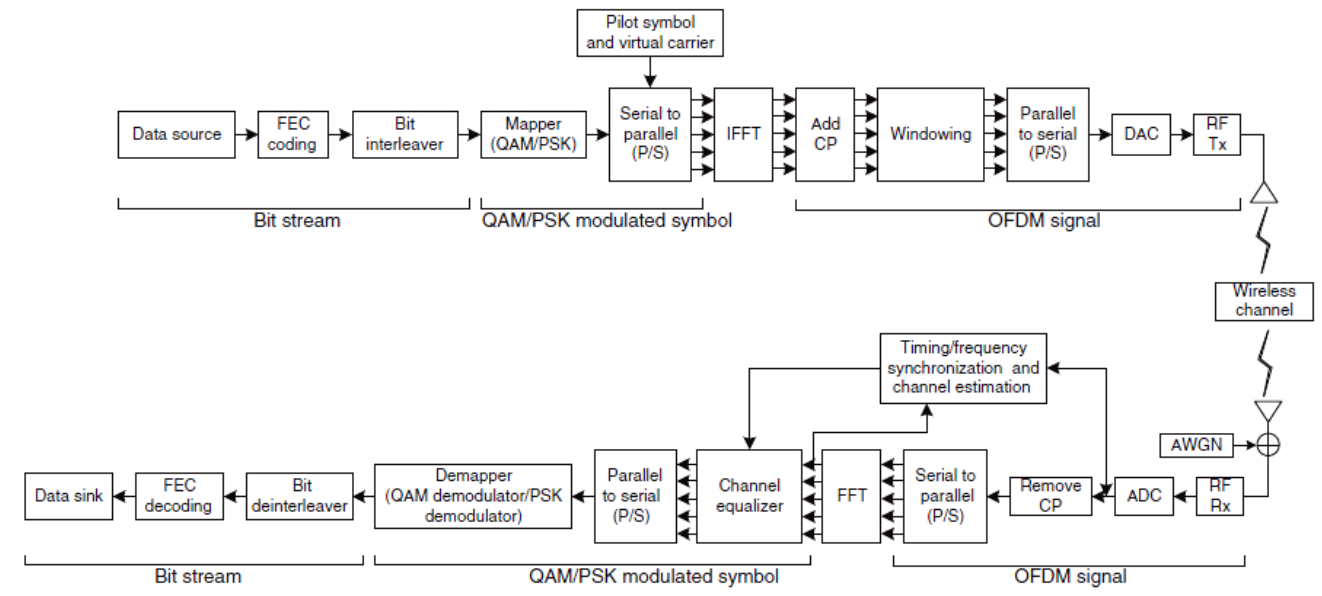

Figure 3. The block diagram of an OFDM System.

Binary data was generated and coded using convolutional encoder. After interleaving data was converted from bits to symbols using M-arry modulation. For channel estimation purposes pilots was inserted into modulated signal, then symbols are converted from serial to parallel substream with size equal to the number of subcarriers. Those substreams are modulated using IFFT circuit. The cyclic prefix (CP) was added to eliminate ISI and inter carrier interference (ICI ). For transmission purposes, data was converted from parallel to serial one. At the receiver side, the received signal, after CP removing, is converted from serial to parallel, then signal is fed into FFT circuit to get the useful data and pilots which are used to estimate the effect of the channel. The signal is equalized depending on the channel estimation information to compensate the effect of channel. The equalized signal is back converted from parallel to serial stream. The signal is demodulated, deinterleaved, and decoded in order to recover the original bits[7]. 


\subsection{MC-CDma System Mathematical Model}

MC-CDMA scheme spreads the original data on large bandwidth by using a given spreading code and converts the high rate of serial stream to parallel low rate substream then transmits $\mathrm{N}$ chips simultaneously by assigning each chip to a separate carrier, by using OFDM transmitter, so that each input symbol is transmitted on $\mathrm{N}$ subcarriers. By correlating the signal samples at the OFDM outputwith the code sequence used for signal dispreading, the transmitted symbol will be extracted at theoutput of the receiver.MC-CDMA transmitter system is shown by figure 4, where $\mathrm{a}^{\mathrm{u}}[\mathrm{i}]$ represents binary data input sequence belong to the $\mathrm{u}^{\text {th }}$ user at $\mathrm{i}^{\text {th }}$ time.

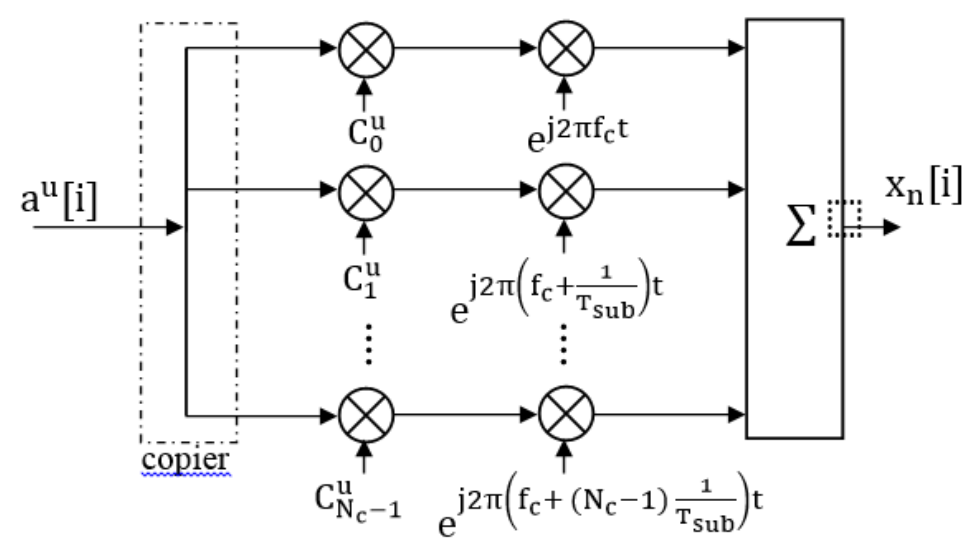

Figure 4. MC-CDMA transmitter.

Considering the case where the length of processing gain $\mathrm{P}_{\mathrm{G}}$ is equal to the number of subcarrier $\mathrm{N}_{\mathrm{c}}\left(\mathrm{N}_{\mathrm{c}}=\mathrm{P}_{\mathrm{G}}\right)$, the $\mathrm{i}^{\text {th }}$ input dataa ${ }^{\mathrm{u}}[\mathrm{i}]$, is first copied to $\mathrm{N}_{\mathrm{c}}$ subchannels and then multiplied by the spreading code $\mathrm{C}_{\mathrm{m}}^{\mathrm{u}}$ which corresponds to the $\mathrm{u}^{\text {th }}$ user, modulated by $\mathrm{N}_{\mathrm{c}}$ subcarriers, then summed and digitized to generate the transmitted MC-CDMA signal $x_{n}[i]$ which is given by [9].

$$
\begin{aligned}
& x_{n}[i]=\sum_{n=0}^{N c-1} X_{m}[i] e^{\frac{j 2 \pi m n}{N_{c}}}, n=0,1, \ldots, N c-1 \\
& \text { Where } \quad X_{m}[i]=\sum_{u=0}^{U-1} a^{u}[i] C_{m}^{u}
\end{aligned}
$$

Where $\mathrm{C}_{\mathrm{m}}^{\mathrm{u}}$ is the spreading code given by (6).

$$
\mathrm{C}_{\mathrm{m}}^{\mathrm{u}}=\mathrm{C}_{0}^{\mathrm{u}}, \mathrm{C}_{1}^{\mathrm{u}}, \ldots, \mathrm{C}_{\mathrm{P}_{\mathrm{G}}-1}^{\mathrm{u}}
$$

The transmitted signal, $\mathrm{x}_{\mathrm{n}}[\mathrm{i}]$ in (4) has a similar formula as that of the OFDM transmitted signal,except that it contains the multiuser multiplexing capability which is introduced basically by the CDMA technology. For simplicity, the index (i) could be omitted in case of one OFDM symbol and assuming multipath fading channel consists of L-paths, then the received signal, $\mathrm{y}_{\mathrm{n}}$, is given by (7).

$$
\mathrm{y}_{\mathrm{n}}=\sum_{l=0}^{\mathrm{L}-1} \mathrm{~h}_{\mathrm{n}, l} \mathrm{x}_{\mathrm{n}-l}+\mathrm{w}_{\mathrm{n}}
$$


Where $\mathrm{h}_{\mathrm{n}, l}$ represents the channel impulse response of the $l^{\text {th }}$ path at time $\mathrm{n}$ and $\mathrm{w}_{\mathrm{n}}$ is the noise component. Without inter carrier interference(ICI ), the received signal in the frequency domain is given by (8):

$$
\begin{aligned}
& \mathrm{Y}_{\mathrm{m}}=\left[\sum_{l=0}^{\mathrm{L}-1} \mathrm{H}_{l}^{0} \mathrm{e}^{-\frac{\mathrm{j} 2 \pi l \mathrm{~m}}{\mathrm{~N}_{\mathrm{c}}}}\right] \mathrm{X}_{\mathrm{m}}+\mathrm{W}_{\mathrm{m}} \\
& =\alpha_{\mathrm{m}} \mathrm{X}_{\mathrm{m}}+\mathrm{W}_{\mathrm{m}}
\end{aligned}
$$

$\mathrm{WhereW}_{\mathrm{m}}$ is the noise component in frequency domain, $\mathrm{L}$ represents the number of paths, And $\alpha_{m}$ represents the multipath fading effect and is given by (9).

$$
\alpha_{m}=\sum_{l=0}^{\mathrm{L}-1} \mathrm{H}_{l}^{0} \mathrm{e}^{-\frac{\mathrm{j} 2 \pi l \mathrm{k}}{\mathrm{N}_{\mathrm{c}}}}
$$

Where $\mathrm{H}_{l}^{0}$ represents the channel transfer function.

If the channel is assumed to be time invariant during the symbol period, then it could be easily compensated by frequency domain equalizer, where the output of the equalizer is given by (10).

$$
\mathrm{X}=\mathrm{H}^{-1} \mathrm{Y}^{\mathrm{T}}(10)
$$

Where $\mathrm{H}^{-1}$ is the estimated invers channel transfer function.

Based on equations $(7,8,10)$, Figure 5 shows the channel estimation and equalization system for MC-CDMA receiver which is already adopted in this paper.

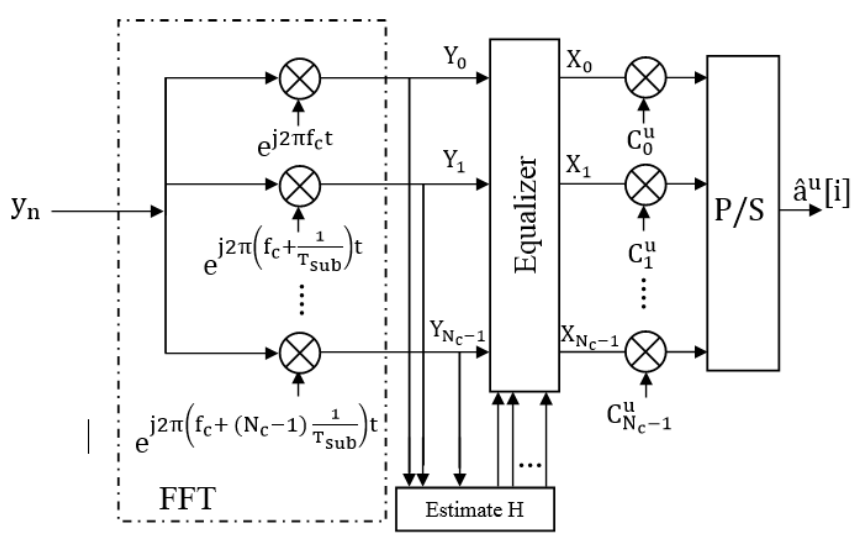

Figure 5. MC-CDMA receiver.

\section{Simulation AND Results}

The system simulation is carried out using MC-CDMA Simulator, designed and built in MATLAB to study the performance of MC-CDMA system for different lengths of processing gain, number of paths, coding ratios of the convolutional encoder, number of users and interleaver.

\subsection{MC-CDMA Simulator}

In this section, a simulator built for the uplink scenario of MC-CDMA system is described. It is composed of four basic units to simulate the transmitter, channel, receiver and BER calculator. 


\subsubsection{TransmitTer SECTION}

MC-CDMA transmitter block diagram is shown in Figure 6.

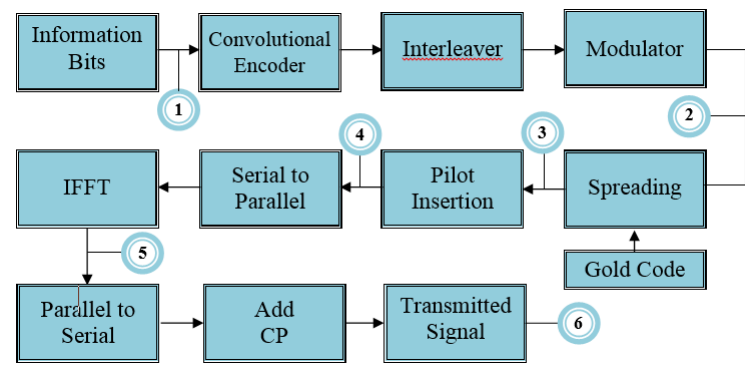

Figure 6. Structure of the MC-CDMA transmitter.

The information bits are generated at 1 in Figure 6 for number of users. These binary bits are coded by using a convolutional encoder with different coding ratios of $1 / 2,2 / 3$ and 3/4. Convolutional encoder is performed according to IEEE 802.11a standard and is built as shown in Figure 7with six Shift Registers (SR)[10].

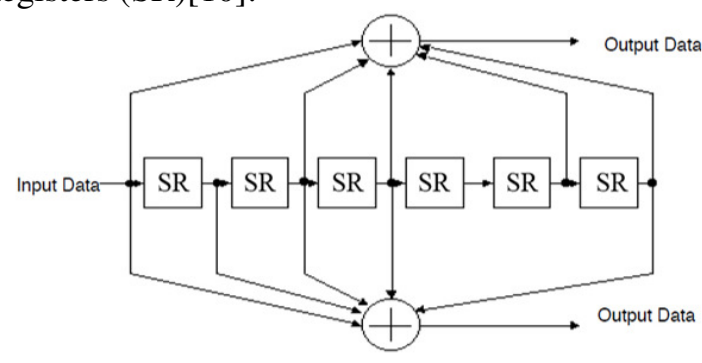

Figure 7. Convolutional encoder structure.

Higher rates $(2 / 3 \& 3 / 4)$ are derived from the same structure by employing "puncturing". Some of the encoded bits in the transmitter will be omitted using Puncturing procedure, thus reducing the number of transmitted bits and increasing the coding rate. At the receiver a "zero" will be inserted into the convolutional decoder on the place of the omitted bits. In this case Viterbi algorithm is recommended for the decoder. Table (1) shows the specifications of the IEEE 802.11a Convolutional encoder[10].

Table 1. The IEEE 802.11a Convolutional encoder specifications.

\begin{tabular}{|c|c|c|c|c|c|c|}
\hline $\begin{array}{l}\text { Coding } \\
\text { ratio }\end{array}$ & $\begin{array}{l}\text { No. of shift } \\
\text { register }\end{array}$ & $\begin{array}{l}\text { Constraint } \\
\text { Length }\end{array}$ & Trellis & $\begin{array}{l}\text { Traceback } \\
\text { length }\end{array}$ & $\begin{array}{l}\text { Decision } \\
\text { type }\end{array}$ & $\begin{array}{l}\text { Puncture } \\
\text { matrix }\end{array}$ \\
\hline $1 / 2$ & 6 & 7 & $133_{8} 177_{8}$ & 34 & Soft & None \\
\hline $2 / 3$ & 6 & 7 & $133_{8} 177_{8}$ & 34 & Soft & {$\left[\begin{array}{llll}1 & 1 & 1 & 0\end{array}\right]$} \\
\hline $3 / 4$ & 6 & 7 & $133_{8} 177_{8}$ & 34 & Soft & {$\left[\begin{array}{llllll}1 & 1 & 1 & 0 & 0 & 1\end{array}\right]$} \\
\hline
\end{tabular}

The coded bits are interleaved by using an interleaver. The interleaved bits are modulated (mapped) to data symbols according to the symbol modulation type which transforms the binary bits into complex data symbols according to the value of modulation index (M). In this paper; 16QAM modulation type is taken into consideration. The spreading operation was performed using Gold code, which is chosen here due to its good cross correlation property, which is an essential 
requirement for CDMA system, where many users share the same medium and to assuring the ability for the receiver to distinguish between them especially in the reverse-link (uplink) case where the transmission is subject to asynchronous behavior between the different transmitted users [11].Figure 8 show a Gold code generated by using two preferred Pseudo Noise (PN) codes. Polynomials combination are used $(5,2)$ and $(5,4,3,2)$ configurations to generate the Gold code with $\mathrm{PG}=31$.

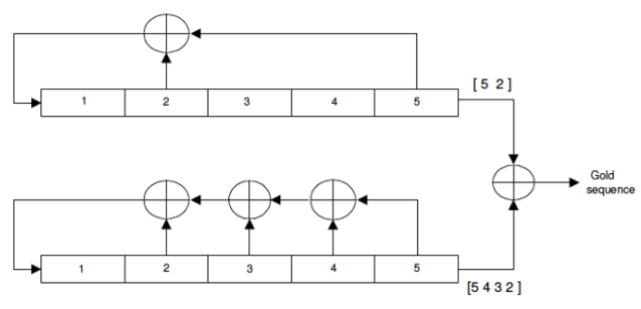

Figure 8. Gold code generation.

The polynomials are fixed while the initial conditions of the registers are varying to generate a group of codes where each code is allocated for a specific user. Table (2) shows the properties of the Gold code used in the simulator where the processing gain of 31, 63, 127 and 255 are taken into consideration. In this paper, the processing gain of 127 is chosen as an upper limit because more higher processing gain leads to decreasing in the transmission bit rates.

Table 2. Code polynomials.

\begin{tabular}{|c|c|c|c|c|}
\hline $\begin{array}{l}\text { Processing } \\
\text { Gain }\end{array}$ & $\begin{array}{c}\text { First } \\
\text { polynomial }\end{array}$ & $\begin{array}{c}\text { Second } \\
\text { polynomial }\end{array}$ & $\begin{array}{c}1^{\text {st }} \text { initial } \\
\text { Condition }\end{array}$ & $\begin{array}{l}2^{\text {nd }} \text { initial } \\
\text { Condition }\end{array}$ \\
\hline 31 & $x^{5}+x^{2}+1$ & $\begin{array}{l}x^{5}+x^{4}+ \\
x^{3}+x^{2}+1\end{array}$ & $\begin{array}{l}00000 \text { to } \\
11111\end{array}$ & 00000 to 11111 \\
\hline 63 & $x^{6+x+1}$ & $\begin{array}{l}x^{6+} x^{5+} \\
x^{2}+x+1\end{array}$ & $\begin{array}{l}000000 \text { to } \\
111111\end{array}$ & 000000 to 111111 \\
\hline 127 & $x^{7}+x^{3}+1$ & $\begin{array}{l}x^{7}+x^{3}+x^{2}+ \\
x+1\end{array}$ & $\begin{array}{l}0000000 \text { to } \\
1111111\end{array}$ & $\begin{array}{l}0000000 \text { to } \\
1111111\end{array}$ \\
\hline$\vdots$ & $\begin{array}{c}\mathrm{x}^{8}+\mathrm{x}^{7}+\mathrm{x}^{6}+\mathrm{x}^{5}+\mathrm{x}^{2}+1 \\
\vdots \\
\vdots\end{array}$ & $\begin{array}{c}\mathrm{x}^{8}+\mathrm{x}^{7}+\mathrm{x}^{6}+1 \\
\vdots \\
\vdots\end{array}$ & $\begin{array}{c}00000000 \text { to } \\
11111111 \\
\vdots\end{array}$ & $\begin{array}{c}00000000 \text { to } \\
11111111 \\
\vdots\end{array}$ \\
\hline
\end{tabular}

Figure 9a shows the Gold code waveform for the first user of 31 chips. The Gold code has the best autocorrelation function when there is no lagging between its chips (chip index $=0$ ) as shown in Figure 9b where the autocorrelation value is equal to the length of the code. Autocorrelation $\&$ cross correlation values are bounded by either $-1,-t\left(L_{s}\right)$ or $t\left(L_{s}\right)-2$ where $\mathrm{L}_{\mathrm{s}}$ is the number of shift registers and $t\left(\mathrm{~L}_{\mathrm{s}}\right)$ is given by (11)[11].

$$
t\left(L_{s}\right)=\left\{\begin{array}{cc}
2^{\left(\left(L_{s}+1\right) / 2\right)}+1 & , \text { for odd } L_{s} \\
2^{\left(\left(L_{s}+2\right) / 2\right)}+1 & , \text { for even } L_{s}
\end{array}\right.
$$

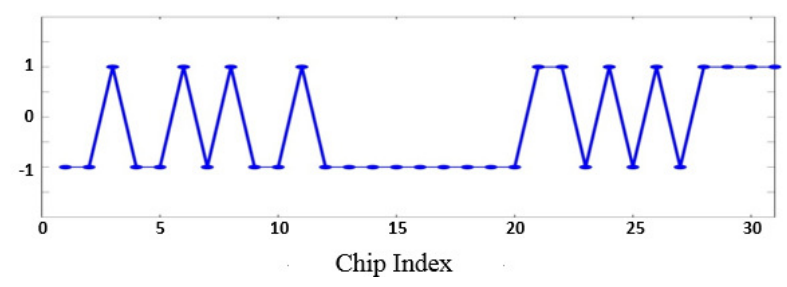

(a) Gold code for first user. 
International Journal of Computer Science \& Engineering Survey (IJCSES) Vol.6, No.3, June 2015

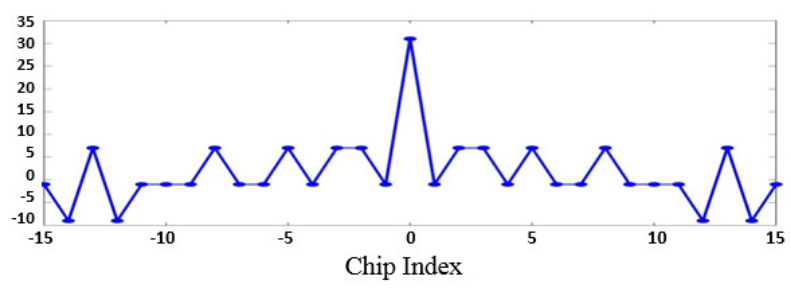

(b) Autocorrelation of first Gold code.

Figure 9. Characteristics of first user Gold code.

The second user Gold code waveform is shown by Figure 10a.For the case of 31 Gold code, figure $10 \mathrm{~b}$ shows the cross correlation between two Gold codes. The cross correlation values are either $-1,-9$ or 7 .

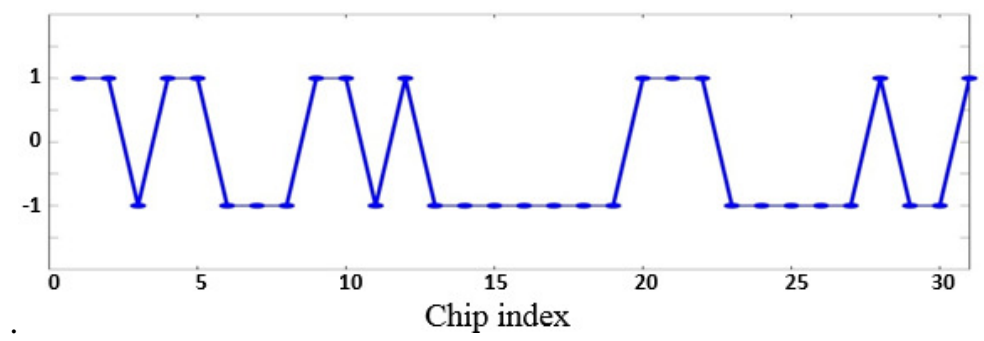

(a) Gold code for second user.

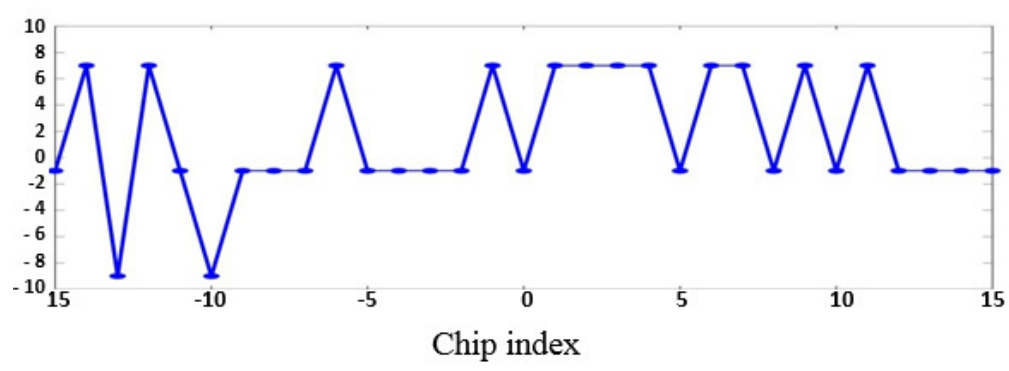

(b) Crosscorrelation between first and second user.

Figure 10. Correlation between two users.

A specific Gold code is allocated for each user. The spreading process is achieved by multiplying each symbol by its allocated code as shown in Figure 11and checked at point 3 in Figure 6.

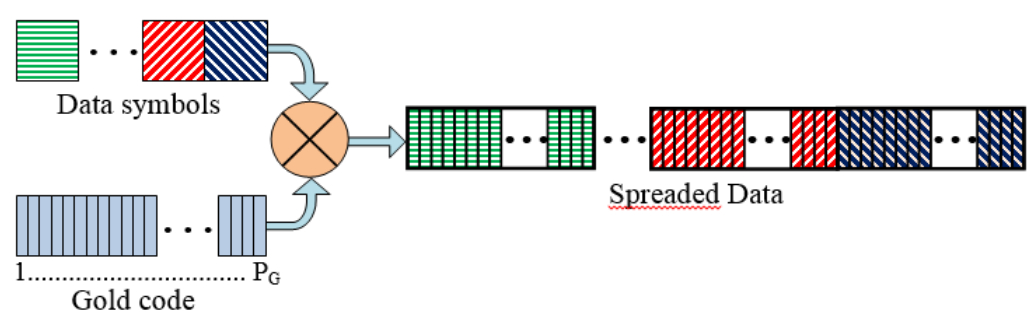

Figure 11. Spreading Process. 
The pilot insertion process is used to insert pilots with known values in the transmitter and the receiver units. This could be done by choosing a Comb type estimator proposed in this paper. In the proposed Comb type, the number of pilots is chosen to be 12, because in IEEE802.11a standard it is specified that only 48 subcarriers are used for data in the OFDM symbol and the 16 subcarriers, including nulls, to achieve a 64-point for the IFFT implementation. Figure 12 show the replacement of the 12 data subcarriers by those of 12 pilots and checked at point 4 in Figure 6 .

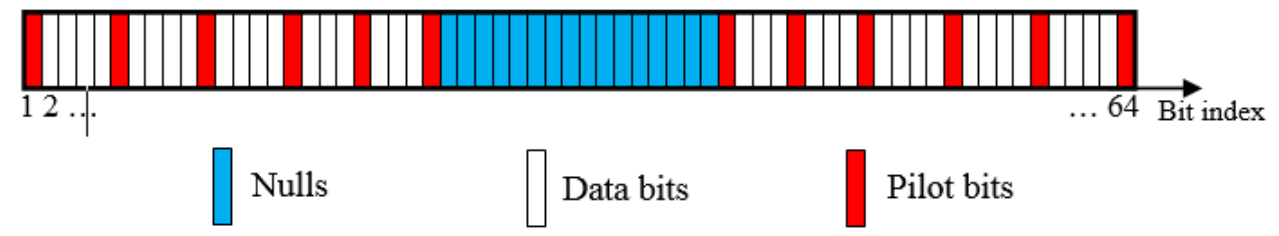

Figure 12. Pilot insertion in Comb type.

The serial stream is converted into 64 parallel substreams which are equal to the size of IFFT circuit. The IFFT circuit modulates each chip of data to the subcarrier where the IFFT circuit ensures the orthogonality between subcarriers and checked at point 5 in Figure 6.The parallel substreams are reconverted to serial streams. The cyclic prefix $(\mathrm{CP})$ is added by copying the last part with length of 16 (equivalent to $T_{s} / 4$ ) resulting in 80 bits symbol length as shown in Figure 13.

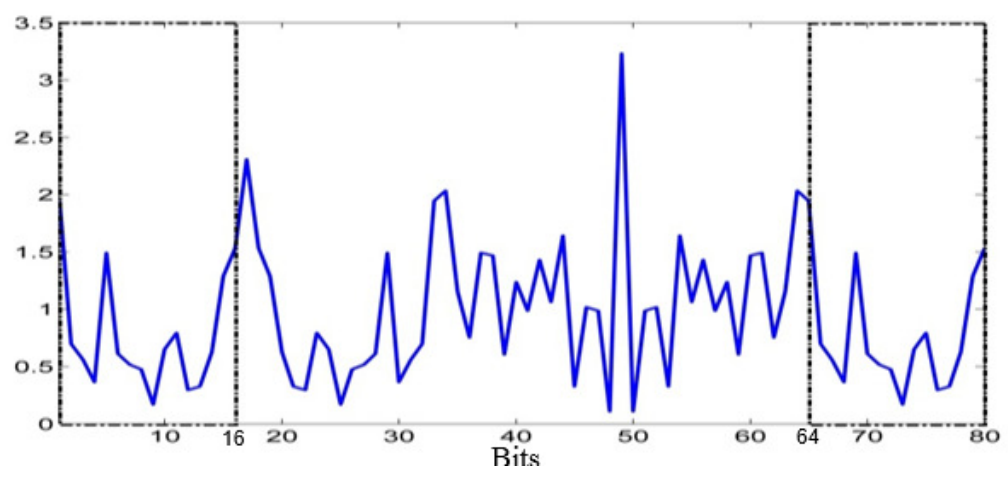

Figure 13. Adding cyclic prefix.

Finally the MC-CDMA symbols are transmitted to the mobile radio channel at point 6 in Figure 6.

\subsubsection{Mobile Radio Channel Section}

To include the effect of the multipath fading channel and Additive White Gaussian Noise (AWGN), the mobile radio channel is divided into two parts as shown in Figure 14.Multipath Rayleigh fading channel is considered in this paper. The uplink case is taken into consideration where each user is affected by certain multipath channel and the faded signals from different users are added together. The last step is represented by adding the AWGN effect before the signal reaches the receiver. All the processes which established at the transmitter site was reversed at the receiver site to get the transmitted message by considering perfect carriers and symbol synchronization. 


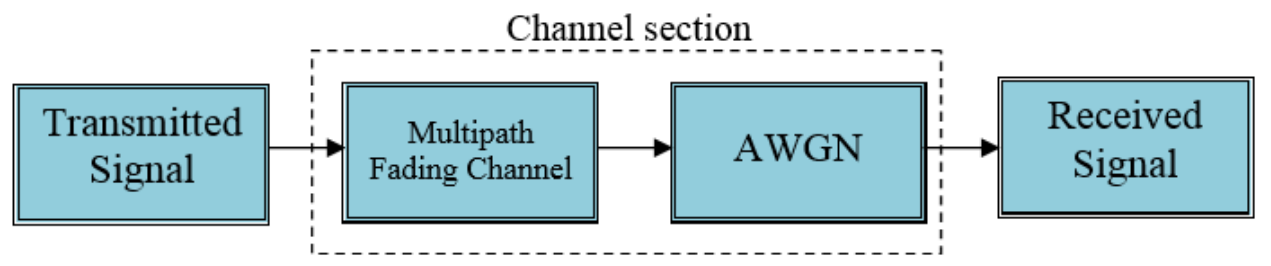

Figure 14. Channel section.

\subsection{BER EVALUATION}

The BER calculation is performed by comparing the transmitted information bits with the received bits. The BER process was evaluated using Monty Carlo principle by taking 200 BER iterations and taking the average to get more accurate results. Finally the BER is plotted for different values of $\mathrm{E}_{\mathrm{b}} / \mathrm{N}_{0}$ to illustrate the performance of the MC-CDMA system. The system design parameters used in this MC-CDMA simulator are summarized in Table (3) and the basic flowchart is shown in Figure 15.

Table 3. Summary of simulation parameters.

\begin{tabular}{|c|c|}
\hline Parameter & Value \\
\hline No. of subcarriers & 64 \\
\hline No. of data subcarriers & 48 \\
\hline Cyclic Prefix & 16 \\
\hline FFT size & 64 \\
\hline No. of pilots & 12 \\
\hline No. of nulls & 16 \\
\hline Synchronization & Perfect \\
\hline Channel type & Channel A. ITU-R \\
\hline Code type & Comb \\
\hline Channel Estimation type & None, 1/2, 2/3 \& 3/4 \\
\hline Coding rate & $16-\mathrm{QAM}$ \\
\hline Modulation type & $31,63, \& 127$ \\
\hline Processing Gain & $2,5,10, \& 15$ \\
\hline No. of users & \\
\hline
\end{tabular}


International Journal of Computer Science \& Engineering Survey (IJCSES) Vol.6, No.3, June 2015
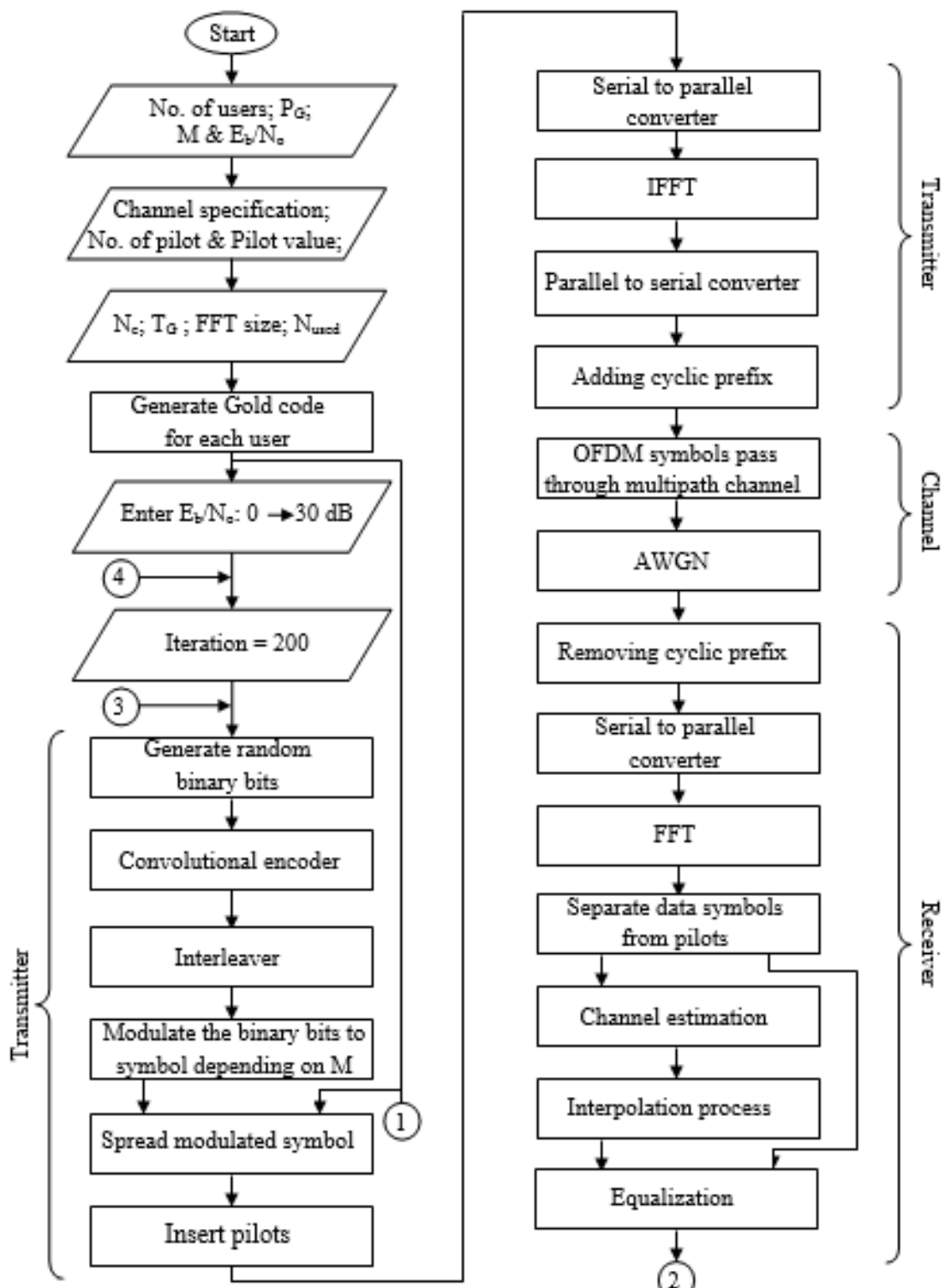

(2)

..... to be continued 
International Journal of Computer Science \& Engineering Survey (IJCSES) Vol.6, No.3, June 2015

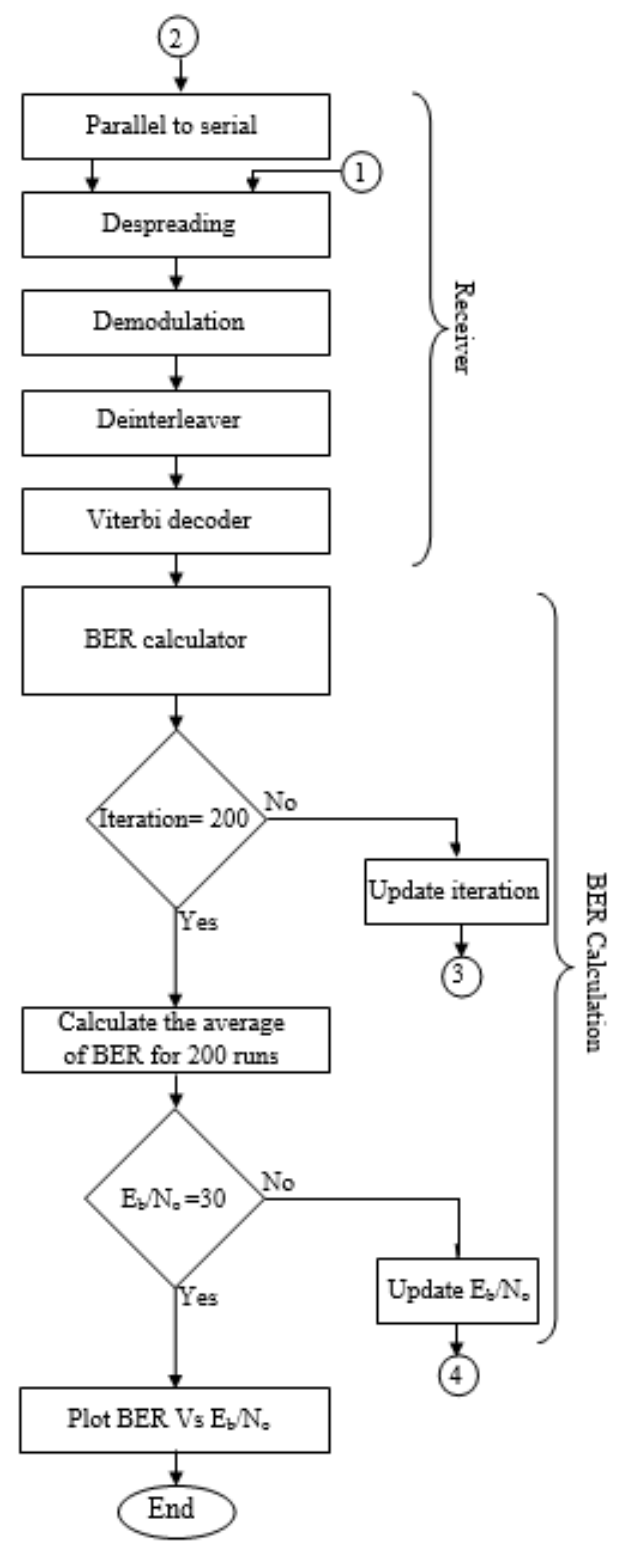

Figure 15. MC-CDMA simulator flowchart.

\subsection{PeRformanCE OF MC-CDMA:}

\subsubsection{Effect of Processing Gain on Ber:}

The effect of varying the processing gain $\left(\mathrm{P}_{\mathrm{G}}\right)$ on the performance of the MC-CDMA are shown in Figure 16 by varying $P_{G}$ from 31 to 63, and 127 for 2 users. It is clear from Figure 16 that BER becomes more better as $\mathrm{P}_{\mathrm{G}}$ increased. 
International Journal of Computer Science \& Engineering Survey (IJCSES) Vol.6, No.3, June 2015

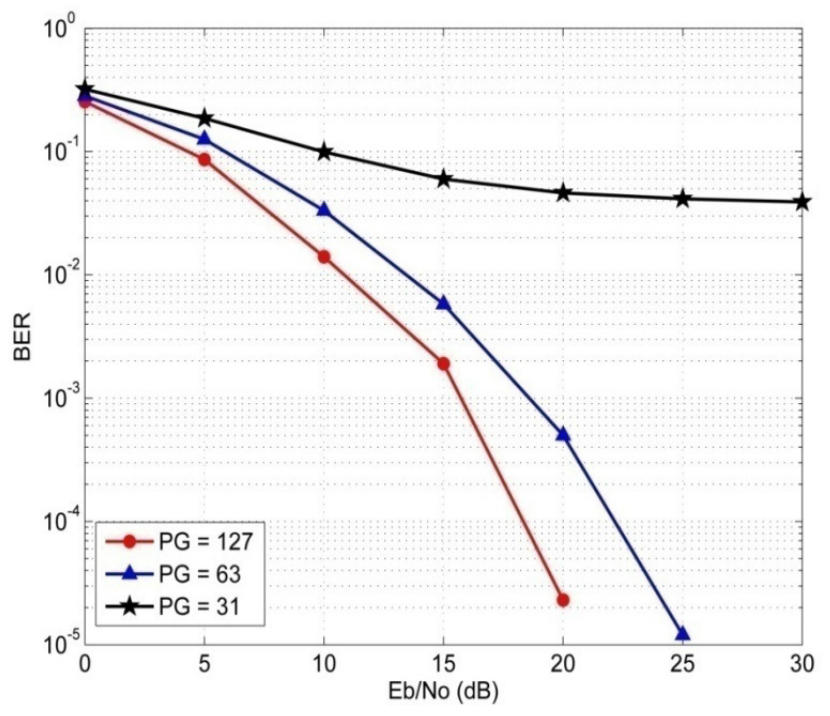

Figure 16. Effect of processing gain on MC-CDMA performance.

\subsubsection{Effect Of Number Of Paths On Ber}

Figure 17 shows the effect of number of channel paths on the BER of the system for 2 users for $1,2,3$ and 4 paths.It is clear that more degradation in system performance occurs as the number of paths increases.

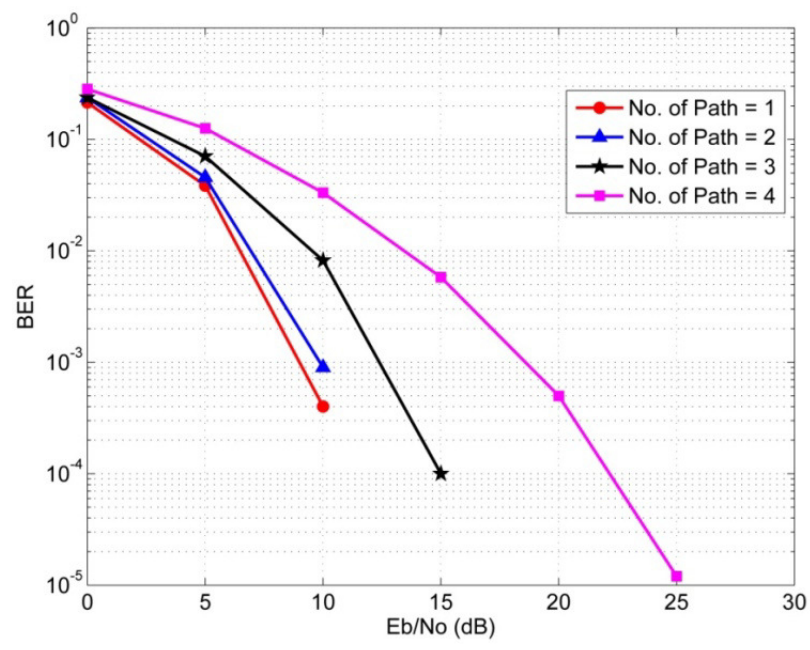

Figure 17. Effect of number of paths on MC-CDMA performance.

\subsubsection{EfFect Of Code Ratio Of Convolutional Encoder ON Ber:}

Convolutional encoder is used to handle the deep fading caused by the channel. Figure 18shows the effect of using different coding ratios for 2 users. 
International Journal of Computer Science \& Engineering Survey (IJCSES) Vol.6, No.3, June 2015

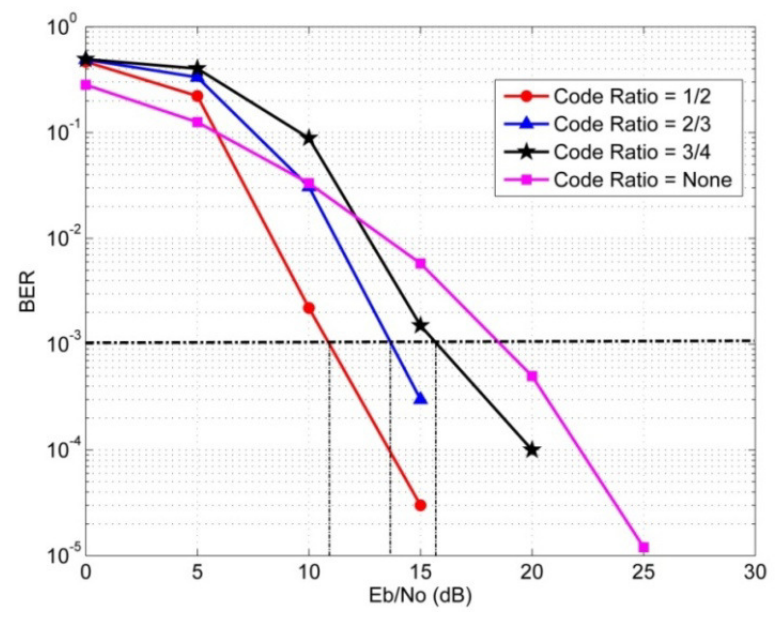

Figure 18. Effect of coding ratio on MC-CDMA performance.

From Figure 18, it is clear that for reference level $B E R=10^{-3}$ at the receiver, the $E_{b} / N_{o}$ needs to be $11 \mathrm{~dB}, 13.5 \mathrm{~dB}$, and $15.5 \mathrm{~dB}$ for code ratio of (1/2), for (2/3) and for (3/4) respectively. Also it could be noticed that for $\mathrm{E}_{\mathrm{b}} / \mathrm{N}_{0}$ less than $6 \mathrm{~dB}$ the system performance is better in case of no coding.

\subsubsection{EFFECT OF NuMBER OF USERS ON BER:}

Figure 19shows the effect of increasing the number of active users on the system performance. From Figure 19, it is shown that the system is failed to response to more than 2 users, since we deal here with a conventional detector, because diversity based detector using Rake receiver is out of the scope of this paper. By using 16-QAMarray modulation and a convolutional encoder of coding ratio (1/2), we can achieve a best MC-CDMA system performance when applying interleaver technique as shown in Figure 20.

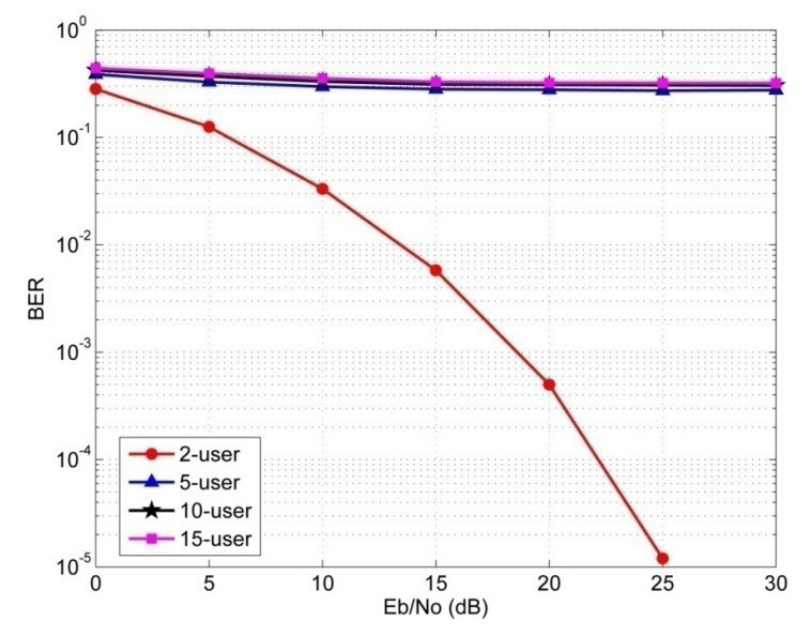

Figure 19. Effect of number of users on MC-CDMA performance. 


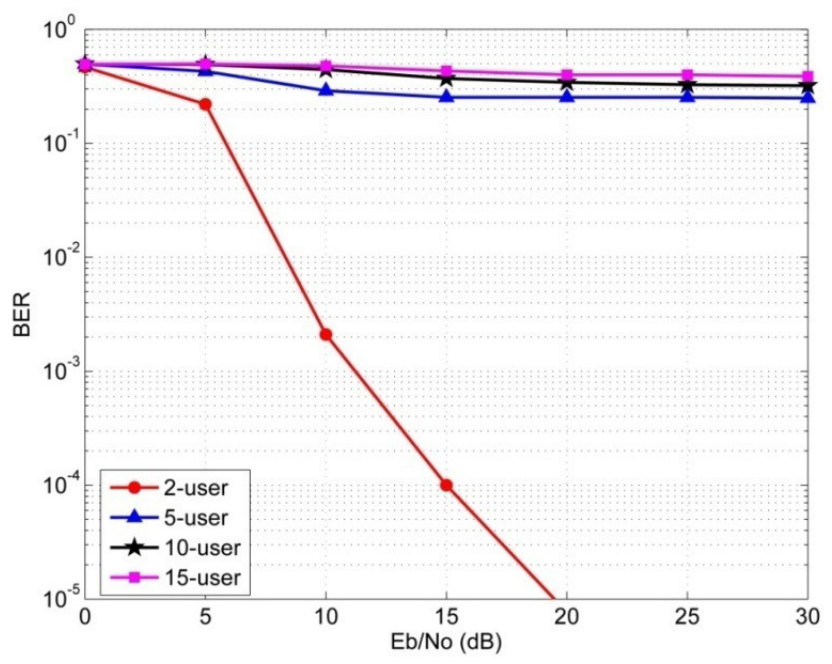

Figure 20. Effect of interleaver on MC-CDMA performance.

\section{CONCLusion}

The combination between OFDM technology and CDMA technology resulting an attractive high speed wireless MC-CDMA communication system. The obtained results showns that the performance of the MC-CDMA is affected by different parameters such as processing gain, number of paths, number of active users, coding ratio of convolutional encoder, and interleaver.MC-CDMA system performance becomes better by increasing the processinggain, decreasing number of paths, and decreasing the coding ratio. As the number of users increases, multi access interference(MAI) increases, causing a degradation in system performance. We can conclude also, depending on the obtained results, that MC-CDMA system performance look better for higher processing gain lower code ratio using interleaver.

\section{REFERENCES}

[1] H.Schulze and C.Luders, Theory and Applications of OFDM and CDMA. Southern Gate, Chichester: John Wiley and Sons Ltd,2005.

[2] K.Fazel and S. Kaiser, Multi-Carrier and Spread Spectrum Systems. Southern Gate, Chichester: John Wiley and Sons Ltd,2003.

[3] A.Mourad, On The System Level Performance of MC-CDMA Systems in The Downlink" Ph.D. dissertation, Rennes Univ.,France, 2006.

[4] W.M.Abdul-Latef, "Performance Improvement of Cellular Communication Systems Using MIMO OFDM”, M.S. thesis, Dept. Elect. Eng., Mosul Univ., Iraq, 2006.

[5] Reem Sultan "Evaluating the Capaciyt of CDMA using SDMATechnique", Thesis at the University of Mosul, College of Engineering.2012.

[6] U.S.Goni, and A.M.Turkmani, "BER performance of a direct-sequence CDMA system in multipath fading mobile radio channels with Rake reception," Vehicular Technology Conference, 1994 IEEE 44th, ISSN: 1090-3038, Vol.2, pp.747 - 751, Stockholm, 1994.

[7] S.Cho, J. Kim, W.Y.Yang and C.G. Kang " MIMO-OFDM Wireless Communications With MATLAB ", 1st Ed., John Wiley and Sons (Asia) Ltd, Singapore, 2010.

[8] S.Hara and R.Prasad, "Overview of Multicarrier CDMA", Communications Magazine, IEEE, Vol.35, No.12, PP 126 - 133, December 1997.

[9] W.G.Jeon, K.H.Chang and Y.S. Cho, "An Equalization Technique For OFDM and MC-CDMA in a Time-Varying Multipath Fading Channels", Acoustics, Speech and Signal Processing, IEEE International Conference, Vol.3, PP 2529 - 2532, Munich, Germany, (21-24) April 1997. 
[10] IEEE Std. 802.11a-1999, "Part 11: Wireless LAN Medium AccessControl (MAC) and Physical Layer (PHY) specifications High-speed Physical Layerin the 5 GHz Band", 1999.

[11] B.G Lee and B. Kim, "Scrambling Techniques for CDMACommunications", Kluwer Academic Publishers, USA, 2002.

\section{Authors}

1.A.M Abdulsattar was born in Mousel-Iraq on 1954. Lecturer at Alhdba University College-Mousel-Iraq. R\&D contribution and consultant in wireless communication. Received BSc degrees from MTC College-Baghdad in 1977. Received MSc and Ph.D. degrees from ENSAE-France in 1979 and 1983 respectively. From 1983 to 1987 Lecturer at MTC College-Baghdad- Iraq. From 1987 to 2004 Researcher at Industrial sector for development of Electronic and Communication systems. From 2004 to 2006 contribute in development of a privet sector companies for wireless applications. From 2006 to 2015, Lecturer at Mousel University and Alhdba university college-Mousel-

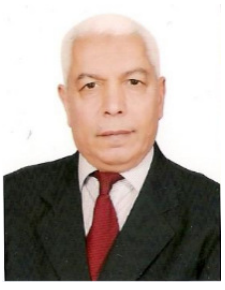
Iraq.Having many Publications in local and International magazines in the digital communication sector.

2.A. D. Alwazzanwas born in Mousel- Iraq on 1985. Working for privet sector in wireless communication services. He received the B.Sc. degree from University of Mosul, Mosul, Iraq in 2008, the M.Sc. degree from University of Mosul, Mosul, Iraq, in 2012.Consultant in wireless communication.

3. KAYDAR MAJEED QUBOA was born in Mosul, Iraq, in 1953. He received the B.Sc. degree from University of Mosul, Mosul, Iraq, in 1976, the M.Sc.degree from University of Mosul, Mosul, Iraq, in 1979 and the Ph.D. degree from the University of Salford, Greater Manchester, United Kingdom, in 1990, all in electrical engineering. He joint the Electrical Engineering Department, College of Engineerin, University of Mosul since 1977. He was the Head of Communication Engineering Department, College of Elrectronics, University of Mosul, from 2002 to 2006. Now he is an Asst. Professor in Electrical Engineering Department, University of Mosul, Mosul, Iraq. His area of interest

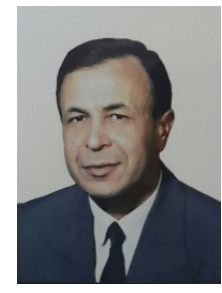
is the effects of EMF on biological materials. 